\title{
A Comparison of Self-Perceived Clinical Competencies in Primary Care Residency Graduates
}

\author{
FRANK M. BIRO, DAVID M. SIEGEL, RUTH M. PARKER, AND MATTHEW W. GILLMAN \\ Department of Pediatrics, University of Cincinnati College of Medicine, Cincinnati, Ohin 45229 /F.M.B.J: \\ Lniversity of Rochester School of Medicine and Dentistry, Rochester, New York 14621 [D..14.S. I: Department of \\ Internal Medicine, Emory University School of Medicine, Atlamta, Georgia 30345 /R.11.P./: and \\ Boston University School of Hedicine, Boston. Massachusetts (02130 [.M.IH.G.J
}

\begin{abstract}
One hundred seventy-eight graduates from four primary care residency training programs with common hospital sites (medicine/pediatrics, 72; family medicine, 29; pediatrics, 35; and internal medicine, 42) responded to a mailed survey questionnaire regarding distribution of professional time and self-perceived clinical competencies. Most of the internists, family physicians, and internist/pediatricians (MED/PED) were in primary care, and $57 \%$ of the pediatricians were subspecialists. Respondents rated each of 24 clinical vignettes as to their level of comfort in managing the patient problems presented. MED/PED and pediatricians responded similarly to all the infant, child, and adolescent cases. Family physicians were less comfortable in managing the complicated neonatal situations but more comfortable with adolescent health care than the MED/PED or pediatricians. MED/ PED reported greater comfort than family physicians in complex internal medicine issues, but less than internists in intensive care and geriatric consultation. Significant differences in reported competency existed among these primary care practitioners despite substantially overlapping training backgrounds. (Pediatr Res 34: 555-559, 1993)
\end{abstract}

Abbreviations

MED/PED, internal medicine/pediatrics

The need for increased numbers and more equitable geographic distribution of primary care physicians in the United States has been articulated since the 1960 s, leading to expanding medical schools and, more recently, to the consideration of minimum quotas for graduates entering primary care specialties. The latter goal was actively pursued by the federal government with passage of the Health Professions Educational Assistant Act of 1976 (PL 94-484), which provided funding for residency training programs in primary care internal medicine, primary care pediatrics, and family medicine. Although there has been gradual acceptance regarding a priority on preparing medical school graduates to become primary care providers, the means to accomplish this goal continues to be debated. The options

Received March 9, 1993: accepted June 14, 1993.

Correspondence and reprint requests: Frank M. Biro, M.D. Division of Adolescent Medicine. Children's Hospital Medical Center, Elland \& Bethesda Ave., Cincinnati, OH 45229.

Supported in part by Maternal and Child Health Grant OH-964. R.M.P. was a fellow in the Robert Wood Johnson Clinical Scholars Program at University of Pennsylvania School of Medicine at the time of the study. discussed in the literature include the traditional pathways of primary care internal medicine, primary care pediatrics, and family medicine (1-10). Alternative primary care training (11. 12) has been implemented in combined internal medicine/pediatrics residency programs (13-18), and discussions have emerged concerning combining residencies in family medicine and internal medicine (19) or combining all three specialties in residency training $(20,21)$.

Given the diversity of training pathways for primary care providers, we speculated that there would be varying levels of clinical competency among graduates of different training programs. Assessment of clinical competency is a complex challenge that can be approached in a variety of ways (22). Physicians in training can be observed by faculty and other house staff in the clinical situations involving the residency experience. These include: 1 ) direct observation during ward rounds and other training activities by faculty and more senior house staff; 2) selection of patients representing a range of clinical problems (physical examination findings as well as differential diagnosis dilemmas) and observing residents as they work through interviewing, examining, and managing these patients $(23) ; 3$ ) the use of standardized patients (patient actors) $(14,24-29) ; 4)$ performance on standard written evaluations (such as board certification) (30): and 5) self-assessment. We chose to explore the issue of selfperceived clinical competency of physicians graduating from various primary care programs through responses to a series of clinical vignettes designed for this study. We undertook a survey of primary care internal medicine, primary care pediatrics. MED/PED, and family practice residency graduates regarding their present clinical orientation (primary care versus subspecialty), the distribution by age of their patients, and their selfperceived competency in managing a variety of clinical problems.

\section{MATERIALS AND METHODS}

We obtained addresses of graduates from MED/PED training programs listed in the 1987 National Residency Matching Program and mailed survey questionnaires to 112 graduates who had completed combined residencies before July 1986 . Nonrespondents were sent a second survey questionnaire. Details of the full survey instrument are reported elsewhere (31). To obtain responses from comparable groups of graduates from residency training programs, we also mailed confidential abridged survey questionnaires to pediatric, primary care internal medicine, and family medicine graduates from the University of Rochester. The University of Rochester was chosen because these residencies (pediatrics, primary care internal medicine, family medicine, and MED/PED) have a number of rotations in common, and Rochester MED/PED graduates represented $20 \%$ of all MED/PED graduates at the time of the survey. 
The total sample of MED/PED respondents were categorized by year of residency completion. A matching number of graduates from each residency (internal medicine, pediatrics, and family medicine) were randomly selected from within the same year of residency completion. This was done to control for the potential confounding effect of year of residency completion on responses to the survey instrument. The randomly selected group had a gender distribution similar to that of the group not selected. The abridged survey instrument included year of residency completion, clinical hours spent with patients of various age groups, self-declared subspecialty or primary care orientation, and selfperceived clinical competencies, elicited through a series of 24 clinical vignettes. The respondents were asked to report their comfort with current abilities in clinical situations, using a Likert scale listing "very," "somewhat," or "not at all" comfortable (Table 1). The responses of MED/PED graduates were compared with each of the other residency groups, using $\chi^{2}$ analysis. Because of multiple comparisons, we chose the level of significance to be $\alpha<0.01$.

\section{RESULTS}

Overall response rates for the mailed survey questionnaires were $64 \%$ ( 72 of 112 ) for MED/PED, $71 \%$ (29 of 41 ) for family medicine, $85 \%$ ( 35 of 41 ) for pediatrics, and $82 \%$ (42 of 51 ) for internal medicine physicians. The distribution of respondents, grouped by years of residency completion, was $\operatorname{similar}\left(\chi^{2}=\right.$ $1.67, p=0.95$ ), with $52 \%$ finishing residency before 1985 . Because the data regarding self-perceived competencies had few (four of 96 analyses) statistically significant differences (at $p<$ 0.05 ) when analyzed for each residency by year of residency completion, the data were further analyzed without consideration

Table 1. Clinical vignettes survey questionnaire for graduates of primary care training programs

How comfortable are you with your current technical skills and reasoning in the following clinical situations (very, somewhat, not at all)?

1. a. Waiting in the delivery room on an anticipated normal newborn

b. 1a, but infant small for gestation age, with meconium present

c. la, but 32-wk gestation to poorly controlled diabetic with abruption

2. a. Evaluating and managing a $9-$ mo-old with a rash

b. $2 \mathrm{a}$, but with temperature of $40^{\circ} \mathrm{C}$

c. $2 b$, but also having grand mal seizure

3. a. Evaluating and managing a 5 th-grade student with poor grades

b. 3a, but obvious hyperactivity and "soft" signs

c. $3 \mathrm{~b}$, who is also enuretic and just accused of arson

4. a. Anticipatory guidance for a high school cheerleader here for a sports physical

b. $4 \mathrm{a}$, but she has been feeling blue for the past 2 mo

c. 4 b. but who confides in you she's just taken 40 tablets of acetaminophen

5. a. A young adult with dysuria

b. 5a, who drinks a six-pack every weekend, but drinks only on weekends

c. 5a, but drinks every day, often to amnesia

6. a. A 60-y-old male with an acute uncomplicated myocardial infarction

b. 6a, who has mild congestive failure

c. 6 b, who also has significant hypotension and multifocal premature ventricular contractions

7. a. Doing a medical consult on a 70-y-old female with a fractured hip

b. $7 \mathrm{a}$, who had a syncopal episode causing the fall

c. $7 \mathrm{~b}$, who has chest pain perioperatively

8. a. An 85 -y-old nursing home patient with memory loss and weight loss

b. $8 \mathrm{a}$, with new onset incontinence

c. $8 \mathrm{a}$, who arrests on the floor and needs family consultation regarding long-term use of life support measures for years since residency completion. Additionally, of the 12 vignettes involving infants, children, and adolescents, only one vignette was significantly different between primary care and subspecialty pediatricians (vignette $4 \mathrm{~b}$, at $p=.03$ ). Responses were therefore collapsed between primary care and subspecialty pediatricians.

The respondents from the four residency groups had similar total clinical hours (Fig. 1), although they had different distributions among the various groups. Of surveyed internists, $48 \%$ spent less than $4 \mathrm{~h} / \mathrm{wk}$ with patients teenaged or younger, whereas $22 \%$ of surveyed pediatricians spent less than $4 \mathrm{~h} / \mathrm{wk}$ with patients teenaged or older. Alternatively, $86 \%$ of surveyed family medicine graduates and $83 \%$ of MED/PED respondents spent at least $4 \mathrm{~h}$ with both younger (infants and toddlers) as well as older (geriatric) patients.

Respondents were asked to identify whether they were involved in primary care, subspecialty care, or both. There was a significant difference in subspecialty/primary care orientation $\left(\chi^{2}=24.79, p<0.005\right)$. Two of the family medicine graduates $(10 \%)$ described themselves as having a subspecialty orientation (one listed epidemiology, the other nutrition), whereas $38 \%$ of the internal medicine and $33 \%$ of the MED/PED graduates had a subspecialty or primary care/subspecialty orientation. Despite the primary care emphasis of the pediatrics residency training program, over half $(57 \%)$ of the graduates responded that they spent all or part of their time as subspecialists.

The last portion of the survey questionnaire consisted of a series of clinical vignettes evaluating self-perceived competencies in clinical situations involving different age groups, varying degrees of medical complexity, and psychosocial and ethical issues (Table 1). When the responses regarding clinical competencies of MED/PED graduates from the University of Rochester were compared with the responses from the remaining MED/ PED graduates, no vignettes were different at a significance of $p<0.01$. Because there were only 16 University of Rochester MED/PED respondents and the responses of these graduates were similar to MED/PED graduates overall, the remaining analyses used all MED/PED respondents as a group to increase the statistical power of the analysis.

As shown in Table 2, internal medicine graduates felt significantly less comfortable with cases dealing with patients younger than teens. The other three groups of residents felt equally comfortable in the uncomplicated delivery room case. With a complex delivery room case, family medicine graduates felt significantly less comfortable than MED/PED or pediatric graduates. Graduates from MED/PED and pediatric programs reported equal degrees of comfort with the three delivery room cases, as well as the other pediatric-age cases: a toddler with a rash or sepsis, a school-aged child with several behavioral issues. and adolescent care issues (routine care, adjustment difficulties, medically complicated suicidal behavior). Of note, family medicine graduates felt more comfortable with the routine care and psychosocial aspects of adolescent health care than did MED/ PED respondents.

Pediatric graduates were significantly less comfortable with adult and geriatric problems than MED/PED graduates, including issues of substance abuse and sexually transmitted diseases in young adults. Family medicine graduates were less comfortable than MED/PED graduates in specific complex internal medicine problems. There were also several issues in intensive care management of acute myocardial infarction, with which internal medicine graduates were more comfortable than MED/PED graduates.

In paired comparisons of family medicine to internal medicine or pediatrics, family medicine respondents were more comfortable with pediatric problems than internal medicine respondents and with adult medical problems than pediatrics respondents (Table 2). Internal medicine and pediatric graduates were more comfortable with several of the adult and pediatric cases, respectively, than were the family medicine graduates. Family medicine 


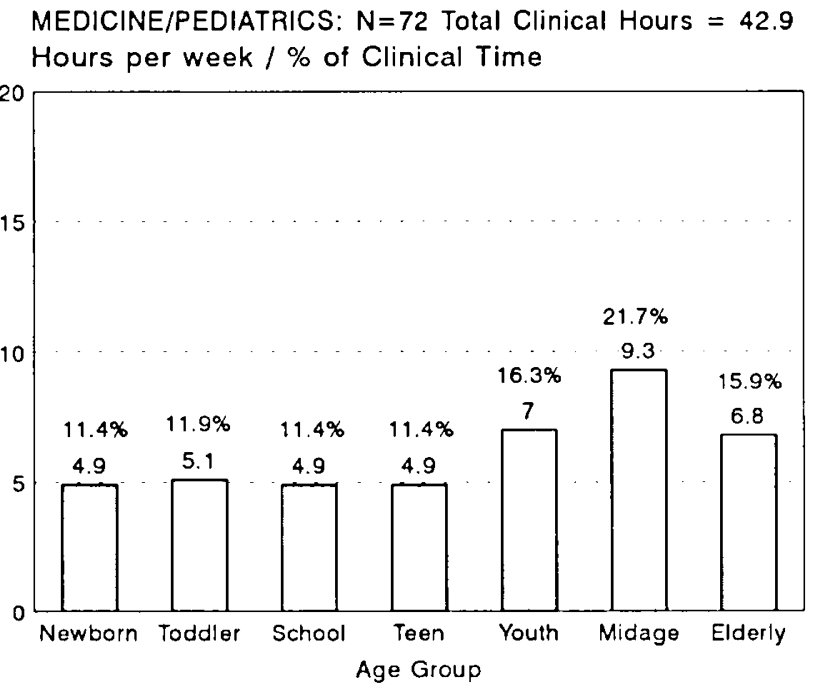

INTERNAL MEDICINE: $\mathrm{N}=42$ Total Clinical Hours $=39.0$ Hours per week / \% of Clinical Time

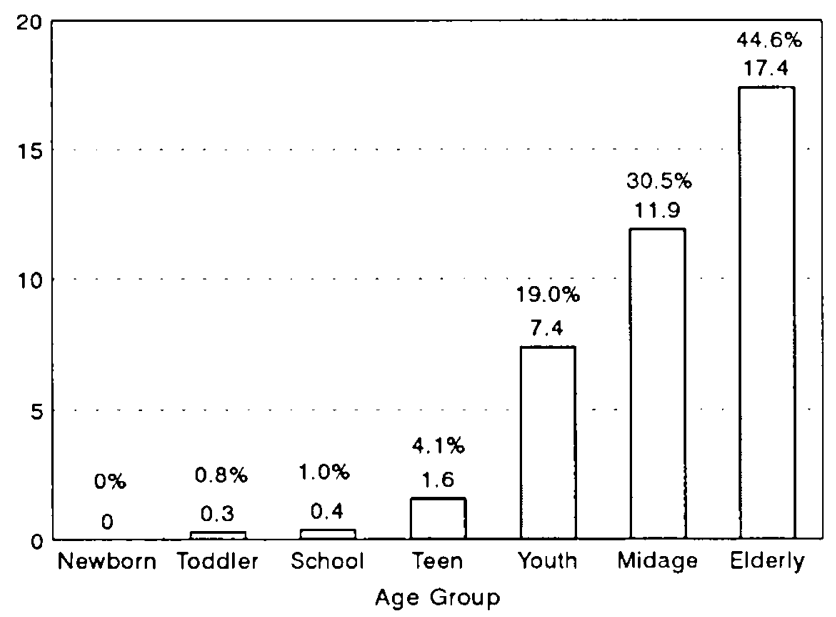

FAMILY MEDICINE: $N=29$ Total Clinical Hours $=42.0$ Hours per week / \% of Clinical Time

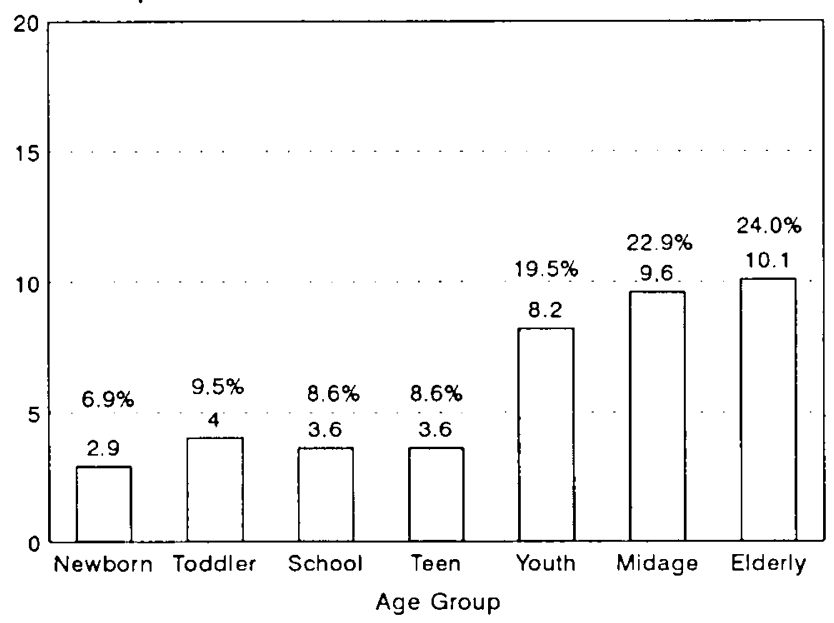

PEDIATRICS: $\mathrm{N}=35$ Total Clinical Hours $=36.8$ Hours per week / \% of Clinical Time

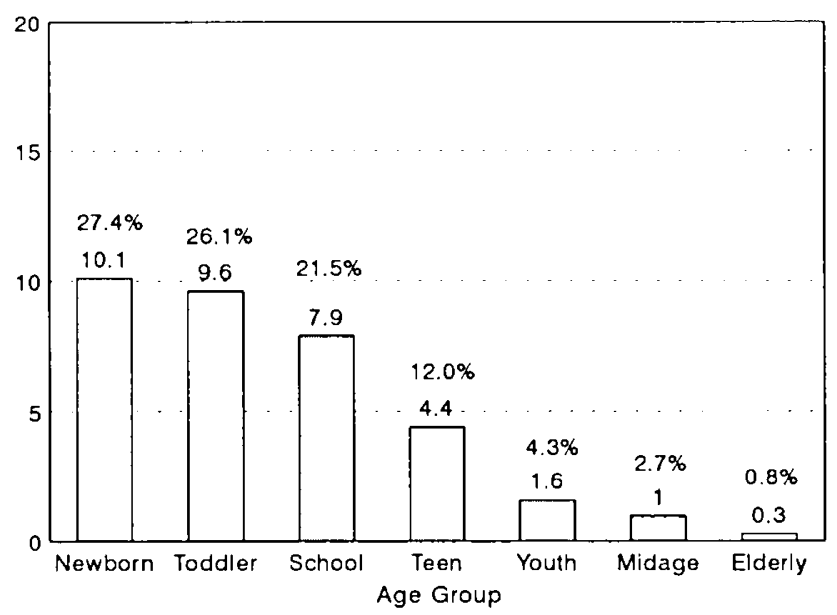

Fig. 1. Mean clinical hours spent per week with specified age group, by primary care residency group; $n=177$.

graduates were more comfortable with the adolescent than internal medicine, pediatrics, or MED/PED graduates (Table 2).

\section{DISCUSSION}

This study of perceived clinical competencies among graduates of primary care training reveals some self-evident findings in terms of age-specific training, as well as some interesting comparisons. Our findings regarding the lack of self-confidence of internists in dealing with infants and toddlers and of pediatricians in dealing with middle-aged and elderly patients are of no surprise, although they do point out the real limitation of patient age-based residency training. Although family medicine and MED/PED graduates are comfortable caring for children and adults, important differences exist. Given the greater depth and exposure experienced by combined MED/PED residents in their training ( 4 y of residency, with a relative emphasis on inpatient and critical care) (31) and a balanced distribution of time spent caring for patients across all age groups in their clinical practice (Fig. 1), as compared with family medicine, there were higher confidence ratings among MED/PED graduates in the areas of complex cases in neonates and adults. There were no situations in which pediatric graduates indicated greater confidence than combined MED/PED residents, whereas internal medicine graduates more consistently indicated their greater confidence compared with MED/PED (and family medicine) graduates in man- aging the complicated myocardial infarction patient and the elderly patients portrayed in the vignettes.

A very revealing area involved adolescent health care. This is a knowledge and skill base claimed by all of the specialties surveyed in this study, but we observed significant differences in confidence ratings. In the case of a young woman with depression and a subsequent toxic ingestion, family physicians were more comfortable in managing the patient, whereas internists tended to be the least comfortable. This may be a reflection of training emphasis. The family medicine residency training program at the University of Rochester includes a comprehensive behavioral science curriculum including training throughout all $3 \mathrm{y}$ of residency, whereas the other specialties provide more intermittent, elective psychosocial training, often in the form of 4-wk experiences. Although our measure of psychosocial competency consists of a single vignette and cannot adequately explore the complex issue of psychosocial problems in clinical practice, this may point to a common deficiency in primary care residency training outside of family medicine. This vignette was chosen as a relatively common problem that the primary care provider must be able to address in caring for adolescents. Preparation of physicians to address the special needs of teenagers involves more than combining internal medicine and pediatric training as is often done in MED/PED training. The required and integrated approach used in family medicine training to teach psychosocial aspects of adolescent health care seems to result in greater physician self-confidence in this important clinical area. 
BIRO ET AL.

Table 2. Comparison of self-perceived competencies of primary care graduates, $\chi^{2}$ analysis*

\begin{tabular}{|c|c|c|c|c|c|c|c|}
\hline & & & \multicolumn{3}{|c|}{$\begin{array}{c}\text { Comparison of MED/PED graduates to other primary } \\
\text { care-oriented specialties }\end{array}$} & \multicolumn{2}{|c|}{$\begin{array}{c}\text { Comparison of family medicine } \\
\text { graduates to internal medicine and } \\
\text { pediatric graduates }\end{array}$} \\
\hline & & & $\begin{array}{l}\text { Compared with } \\
\text { family medicine }\end{array}$ & $\begin{array}{l}\text { Compared with } \\
\text { internal medicine }\end{array}$ & $\begin{array}{c}\text { Compared with } \\
\text { pediatrics }\end{array}$ & $\begin{array}{l}\text { Compared with } \\
\text { internal medicine }\end{array}$ & $\begin{array}{c}\text { Compared with } \\
\text { pediatrics }\end{array}$ \\
\hline \multirow[t]{3}{*}{1} & $\mathrm{a}$ & Normal newborn & 0.084 & $N / A$ & 0.99 & $N / A$ & 0.15 \\
\hline & $\mathrm{b}$ & Small-for-date infant, meconium & $0.040(+)$ & $N / A$ & 0.40 & $N / A$ & $0.005(-)$ \\
\hline & c & Premature infant, abruption & $0.0001(+)$ & $\mathrm{N} / \mathrm{A}$ & 0.45 & $\mathrm{~N} / \mathrm{A}$ & $0.001(-)$ \\
\hline \multirow[t]{3}{*}{2} & a & Toddler with rash & 0.49 & $\mathrm{~N} / \mathrm{A}$ & 0.27 & $N / A$ & 0.52 \\
\hline & b & Plus fever & 0.12 & $\mathrm{~N} / \mathrm{A}$ & 0.43 & $\mathrm{~N} / \mathrm{A}$ & $0.02(-)$ \\
\hline & c & Plus seizures & $0.0001(+)$ & $N / A$ & 0.46 & $N / A$ & $0.001(-)$ \\
\hline \multirow[t]{3}{*}{3} & a & 5th grader, poor grades & 0.06 & $N / A$ & 0.26 & $N / A$ & $0.05(-)$ \\
\hline & $\mathrm{b}$ & Plus attention deficit & 0.20 & $N / A$ & 0.61 & $N / A$ & 0.06 \\
\hline & c & Plus enuresis & 0.81 & $N / A$ & 0.30 & $N / A$ & 0.33 \\
\hline \multirow[t]{3}{*}{4} & a & High school girl sports physical & $0.001(-)$ & $0.023(+)$ & 0.92 & $0.001(+)$ & $0.002(+)$ \\
\hline & $\mathrm{b}$ & Plus depression & $0.05(-)$ & $0.00+(+)$ & 0.52 & $0.001(+)$ & $0.01(+)$ \\
\hline & c & Plus suicidal behavior & 0.21 & 0.11 & 0.79 & 0.10 & 0.27 \\
\hline \multirow[t]{3}{*}{5} & a & Young adult, dysuria & 0.06 & 0.36 & N/A & 0.10 & $N / A$ \\
\hline & $b$ & Plus weekend alcohol & 0.48 & 0.13 & N/A & 0.14 & $\mathrm{~N} / \mathrm{A}$ \\
\hline & c & Plus alcohol to amnesia & 0.77 & 0.11 & N/A & 0.26 & N/A \\
\hline \multirow[t]{3}{*}{6} & a & Acute myocardial infarction & 0.86 & $0.003(-)$ & N/A & $0.05(-)$ & $N / A$ \\
\hline & $b$ & With congestive failure & 0.09 & $0.003(-)$ & $N / A$ & $0.001(-)$ & $\mathrm{N} / \mathrm{A}$ \\
\hline & c & Plus hypotension and dysrhythmias & $0.001(+)$ & $0.01(-)$ & $N / A$ & $0.001(-)$ & $\mathrm{N} / \mathrm{A}$ \\
\hline \multirow[t]{3}{*}{7} & a & Elderly female, fractured hip & 0.91 & $0.02(-)$ & $N / A$ & 0.37 & N/A \\
\hline & $\mathrm{b}$ & With syncope & $0.02(+)$ & $0.03(-)$ & $N / A$ & $0.001(-)$ & $\mathrm{N} / \mathrm{A}$ \\
\hline & c & With perioperative chest pain & $0.001(+)$ & 0.09 & $N / A$ & $0.001(-)$ & $\mathrm{N} / \mathrm{A}$ \\
\hline \multirow[t]{3}{*}{8} & a & Geriatric patient, memory loss & 0.64 & $0.02(-)$ & $\mathrm{N} / \mathrm{A}$ & 0.08 & $N / \Lambda$ \\
\hline & $\mathrm{b}$ & Plus incontinence & 0.69 & 0.22 & $N / A$ & 0.30 & $\mathrm{~N} / \mathrm{A}$ \\
\hline & c & Life support issues & 0.72 & 0.11 & $\mathrm{~N} / \mathrm{A}$ & 0.31 & $\mathrm{~N} / \mathrm{A}$ \\
\hline
\end{tabular}

* N/A, not applicable; (+), more comfortable; $(-)$, less comfortable.

In the case of the patient with dysuria and alcoholism, the pediatricians were uncomfortable. In part, this may be attributed to the wording of the item in which the patient was described as a "young adult." Nevertheless, issues regarding a possible sexually transmitted disease and substance abuse are within the expected curriculum for primary care pediatrics. These pediatric graduates would have been expected to (but did not) describe themselves as confident in these areas, although multiple vignettes may have established a higher degree of confidence in our results.

Studies have been carried out to assess relative performance of internists and family physicians in clinical settings $(32,33)$. Various patient outcomes such as mortality, length of stay, and charges generated were used as the dependent variables in these investigations, and no differences were noted between family physicians and general internists. Patient outcome is one important index of physician competence, but these studies are limited because only inpatient issues were explored, and the subjects involved were restricted to one hospital in each study $(32,33)$. The respondents in the present study, however, practiced in many different hospitals and are involved in both ambulatory and inpatient settings.

In training settings, the use of standardized patients as measures of clinical competency has been extensively studied and found to be valid $(9,17,25-29)$. Self-assessment of clinical competence was chosen for the study given the diversity of residency training, varying years since completion of training, and wide geographics. When dealing with physicians who have completed training and are geographically widespread, this method is practical, albeit subjective. As such, it actually measures the respondents' perception of how well they would deal with the clinical cases presented, without confirming this perception through any external standard. It is an index of self-confidence. Although self-confidence is not necessarily a measure of competence, having a sense of one's capabilities and limitations in clinical practice is an important element of being a qualified physician.
Among primary care internists, pediatricians, and family physicians, we chose to look at physicians with a common site of training, rather than a common site of current practice; our focus was on the effect of different primary care training program curricula. Primary care internal medicine, primary care pediatrics, family medicine, and combined internal medicine and pediatric residencies at the University of Rochester are separate but significantly overlapping programs. Residents from the various primary care training programs were placed in the university hospital and in affiliated community hospitals for various periods of time during their training. often on the same house staff team (for adult or pediatric wards, as appropriate) and there was extensive mixing of full-time faculty, community practitioners, and patients as their teachers. The three designated primary care programs include heavy emphasis on ambulatory services $(20 \%$ to $25 \%$ time commitment). We felt that the setting in Rochester provided an unusual opportunity to compare graduates of separate but similar primary care residency training programs. University-based family medicine graduates, however, may not reflect the comfort/competency level of family medicine graduates from community hospital programs, where there may be limited or no interaction with other specialty residents (e.g. internal medicine or pediatrics).

In addition to the absence of validation of self-perceived competency, a number of other limitations must be considered in interpreting the results of this survey. As an initial study comparing these groups of physicians, the sample sizes were small and our observed trends require testing in a larger sample to improve the power of the study. Additionally, the somewhat lower response rate of MED/PED graduates may reflect that some graduates were purportedly mailed questionnaires by their training programs, rather than through direct mailings by the authors (31). The vignettes used in this study represent a small cross-section of the clinical problems encountered in various age groups, and a more inclusive questionnaire might bring out different self-perceived competencies among these primary care 
providers. Although conclusions were drawn from single vignettes, there was a hierarchial complexity that allowed a further understanding of underlying medical principles. The most extreme vignettes were all appropriate for consultation and sometimes referral, but making that judgment is part of "being comfortable" in managing these clinical situations. Use of a fivepoint, as opposed to a three-point, Likert scale may have been a more sensitive measure, and test-retest reliability was not evaluated. These subjects require further exploration.

It is our impression, based on information provided by these graduates of three primary care training alternatives at the University of Rochester and nationwide graduates of MED/PED residencies, that being a complete generalist is a challenge. Each form of postgraduate clinical preparation has its own particular strengths and weaknesses. If a generic primary care residency is to evolve $(8-12,19,20)$, the strengths of all these forms of training need to be brought together to prepare the provider to become a confident, and competent, generalist.

Acknowledgments. The authors would like to acknowledge Robert A. Hoekelman, M.D., for his careful review and suggestions; Philip R. Khoury, M.S., for his research assistance; and Lynn H. McDermott for secretarial assistance.

\section{REFERENCES}

1. Rogers DE 1985 Internists: more specialists or more generalists? Ann Intern Med 102:702-703

2. Schroeder SA. Showstack JA. Gerbert B 1986 Residency training in internal medicine: time for a change? Ann Intern Med 104:554-561

3. Karpf M. Levey GS 1986 Training internists for the changing medical scene. Ann Intern Med 104:567-568

4. American Academy of Pediatrics Task Force on Pediatric Education 1978 The Future of Pediatric Education. Evanston, IL

5. Charney E 1975 Internal medicine and pediatric residency education for primary care. J Med Educ 50:137-139

6. Petersdorf RG 1975 Internal medicine and family practice: controversies. conflict, and compromise. N Engl J Med 293:326-332

7. Friedman RH 1986 Family practice and general internal medicine: what kind of cooperation makes sense? JAMA 255:2644-2646

8. Smilkstein G 1989 Future primary care: a merger or not. J Fam Pract 29:600

9. Chaney EJ 1989 Future primary care: a merger or not. J Fam Pract 29:600601

10. Perkoff GT 1989 Should there be a merger to a single primary care specialty for the 21 st century. J Fam Pract 29:185-188

11. Geyman JP 1986 Training primary care physicians for the 21st century: alternative scenarios for competitive is. generic approaches. JAMA 255:263t-2635

12. Colwill JM 1986 Education of the primary physician: a time for reconsideration? JAMA 255:2643-2644
13. Greganti MA, Schuster BL 1986 Two combined residency programs in internal medicine and pediatrics. J Med Educ 61:883-892

14. Shumway JM, Ferrari MD 1987 Survey of medicine/pediatrics residency training programs. J Gen Intern Med 2:377-380

15. Siegel DM, Parker RM. Gillman MW, Biro FM 1988 Demographic features and attitudes of program directors of combined internal medicine and pediatrics residencies. Am J Dis Child 142:1104-1108

16. Goldenherg K. Peterson S, Wergowske G, Lemkau J, Kogut MD. Barnes HV 1989 A combined primary care residency in internal medicine and pediatrics. Acad Med 64:519-524

17. Ferrari ND, Shumway JM 1989 Combined internal medicine pediatrics residency training programs. Pediatrics 84:94-97

18. Middelkamp JN 1989 Combined medicine-pediatrics training programs Pediatrics 84:181-182

19. Christiansen RG, Johnson CP. Boyd GE, Koepsell JE, Sutton K 1986 A proposal for a combined family practice-internal medicine residency. JAMA 255:2628-26.30

20. Strelnick AH, Bateman WB, Jones C, Shepherd SD, Massad RJ. Townsend JM. Grossman R, Korin E. Shorow M 1988 Graduate primary care training: a collaborative alternative for family practice, internal medicine. and pediatrics. Ann Intern Med 109:324-334

21. Scherger JE 1989 Should there be a merger to a single primary care specialty for the 21 st century: an opposing view. J Fam Pract 29:189-190)

22. Langsley DG $1991 \mathrm{Medical}$ competence and performance assessment-A new cra. JAMA 266:977-980

23. Woolliscroft JO, Stross JK, Silva J 1984 Clinical competence certification: a critical appraisal. J Med Educ 59:799-805

24. Stillman PL. Swanson DB 1987 Ensuring the clinical competence of medical school graduates through standardized patients. Arch Intern Med 147: 1049-1052

25. Cohen R, Rothman AI, Poldre P, Ross J 199! Validity and generalizability of global ratings in an objective structured clinical examination. Acad Med 66: $545-548$

26. Joorabchi B 1991 Objective structured clinical examination in a pediatric residency program. Am J Dis Child 145:757-762

27. Ainsworth MA, Rogers LP, Markus JF, Dorsey NK, Blackwell TA, Petrusa ER 1991 Standardized patient encounters-A method for teaching and evaluation. JAMA 266:1390-1396

28. Stillman P. Swanson D. Regan MB, Philbin MM. Nelson V, Ebert T, Ley B, Parrino T, Shorey J, Stillman A, Alpert E, Caslowitz J, Clive D, Florek J, Hamolsky M, Hatem C, Kizirian J, Kopelman R. Levenson D. Levinson G, McCue J, Pohl H, Schiffman F, Schwartz J, Thane M, Wolf M 1991 Assessment of clinical skills of residents utilizing standardized patients. Ann Intern Med 114:393-401

29. Tamblyn RM, Klass DJ, Schnabl GK, Kopelow ML 1991 Accuracy of standardized patient presentation. Med Educ 25:100-109

30. Norcini Jj, Day SC. Benson JA. Mainhoff NA 1989 Trends in medical knowledge as assessed by the certifying examination in internal medicine. JAMA 262:24(1)2-2404

31. Biro FM. Gillman MW, Parker RM. Khoury PR. Siegel DM 1990 Surveying graduates of combined internal medicine-pediatrics residency program. Acad Med 65:266-271

32. Franks P. Dickinson JC 1986 Comparisons of family physicians and internists: process and outcome in adult patients at a community hospital. Med Care 24:941-948

33. Hainer BL. Lawlor FH 1988 Comparison of critical care provided by family physicians and general internists. JAMA 260:354-358 